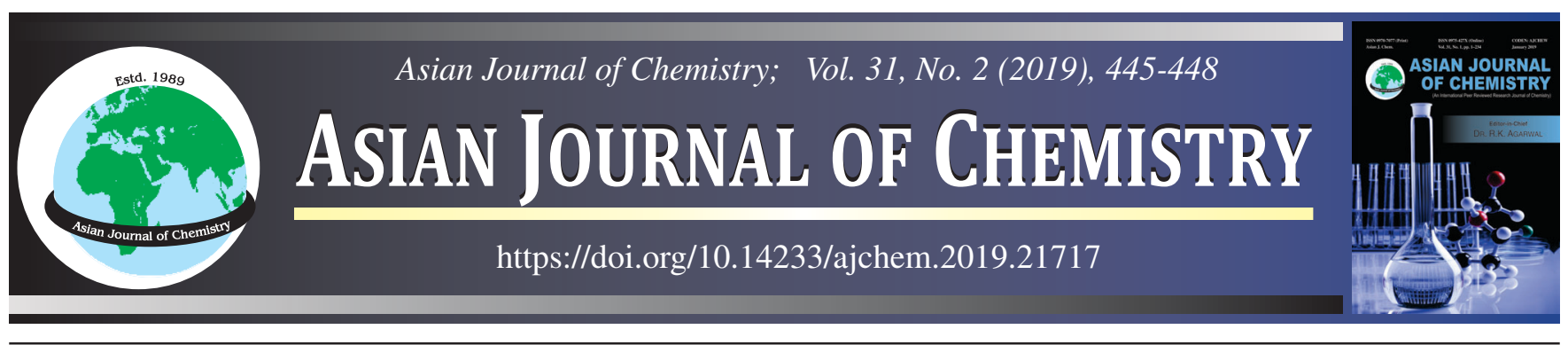

\title{
Antioxidant Activity and Total Phenolic Contents of Dodonaea viscose and Capparis spinosa from Jebal Shuda in Albaha Area of Saudi Arabia
}

Abdalfatah Abdalla Fadlelmula* and Abdulaziz Ali Alomari

Department of Chemistry, Faculty of Science and Arts in Mukhwa, University of Albaha, Albaha 65931, Saudi Arabia

*Corresponding author: E-mail: abdalfatah63@gmail.com

Received: 19 September 2018;

Accepted: 31 October 2018;

Published online: 31 December 2018;

AJC-19224

Capparis spinosa and Dodonaea viscose are commonly known plants in South of Saudi Arabia (Jabal Shuda in Albahah area). They are extremely valued medicinal plants. The variety of active chemicals like flavonoids, tannin and other antioxidants which are responsible of therapeutic properties in these plants, which are vary in their constituents in all plant parts. In this study, the medicinal plants Capparis spinosa and Dodonaea viscose were collected from Jabal Shuda in Albaha Area of Saudi Arabia. Total phenolic content and the effectiveness of the leaves extracts against the free radical scavenging DPPH were carried out. Four different solvents (ethanol, petroleum ether, chloroform, ethyl acetate, and $n$-butanol) were studied and their results were compared. Total phenolic contents expressed as gallic acid equivalent, whereas scavenging capacity for DPPH radical was measured as $\mathrm{IC}_{50}$ values. The elevated total phenolic content $(351.59 \pm$ $0.06 \mathrm{mg} / \mathrm{g} \mathrm{GAE})$ and highest value of antioxidant activity $\left(76.58 \pm 0.024 \%\right.$ lower value of $\left.\mathrm{IC}_{50}, 0.0358 \pm 0.09 \mathrm{mg} / \mathrm{mL}\right) \mathrm{were}$ observed in ethyl acetate extract of $D$. viscose leaves. The $n$-butanol extract of $C$. spinosa leaves exhibited total phenolic content (128.32 $\pm 0.4 \mathrm{mg}$ GAE/g) which was lower than that shown by $n$-butanol leaves extract of $D$. viscose $(231.98 \pm 0.02 \mathrm{mg}$ GAE/g). Leaves extracts of Capparis spinosa and Dodonaea viscose that grow wildly in Jabal Shuda in Albahah area of Southern Saudi Arabia are rich in phenolic compounds which exhibited high antioxidant activity, but Dodonaea viscose was more valued than Capparis spinosa in these compounds.

Keywords: Capparis spinosa, Dodonaea viscose, Phenolic content, DPPH, Antioxidant activity.

ᄂ - - - - - - - - - - - - - - - - - - - - - - - - - - - - -

\section{INTRODUCTION}

The human body produces reactive oxygen species as part of its normal biological activities. However, when their production exceeds the body's ability to eliminate them oxidative stress occurs, leading to damage or alteration of vital regulatory systems in the body. Reactive oxygen was reported to subscribe to bring out several illness involving atherosclerosis, arthritis, cardiovascular disorders, Alzheimer, aging and cancer [1]. In last few years, there was wide interest in use of alternative drugs that use instead of synthetic drugs, particularly those obtained from plants, and as a score of evolution of knowledge where these components have no side effects and are easily available at suitable prices [2].

This study concentrate on investigating of antioxidants of plant source. As the nature considered as a big store of huge number of compounds characterized with therapeutic value, searching for natural resources lead to recognition of comp- ounds that possess potent therapeutic properties [3]. In Arab folklore Capparis spinosa is well known medicinal plant and used to cure different human troubles like gastrointestinal disorder, turbidity, diarrhea, strangury, tenderness, infection and leukaemias. Capparis zeylanica is used in treatment of sickness like spasmolyte, pimples and purge. Capparis species are adduced to be used as modern medicines [3]. Dodonaea viscosa Jacq. is a plant pertinence to the family Sapindaceae. These plants are used in traditional medicine for the curing of several external fungal infections like Tinea versicolor and Tinea capitis [4]. The powdered leaves of $D$. viscosa used to reduce fever characteristics and helpful for various epidermis disorder.

D. viscosa Jacq. is a prevalent medicinal plant and used in traditional treatment as drug for fever, pain in the joints, muscles or fibrous tissue. The plant extract has restrained effects versus most of the microorganism like bacteria and fungi, so inspire potential versus outstanding Gram positive organisms [4]. The phenolic compounds can cut off the series of oxidation

This is an open access journal, and articles are distributed under the terms of the Creative Commons Attribution-NonCommercial 4.0 International (CC BY-NC 4.0) License, which allows others to copy and redistribute the material in any medium or format, remix, transform, and build upon the material, as long as appropriate credit is given and the new creations are licensed under the identical terms. 
reactions by eliminating free radical transition states and prevent the rest of oxidation reactions. In spite of the cell obtains advanced systems of antioxidants, such as glutathione, vitamin $\mathrm{C}$ and vitamin A, however the enough amounts of phenolic compounds or suppression of the antioxidant enzymes may lead to oxidative compression [5].

In addition contemporary studies, aqueous extracts of $C$. spinosa showed numerous therapeutic activities, including antifungal, antibacterial, and antiviral [6]. The aim of current study is to estimate the total phenol contents and to assess the antioxidant activity of Capparis spinosa and Dodonaea viscose, collected from Jabal Shuda in Albaha area of south of Saudi Arabia. Furthermore, we intend to make a comparison between the different extracts of selected solvents so as to define accordingly the best solvent can be use for extraction of phenolic compounds and antioxidants from the plants under taken in this study.

\section{EXPERIMENTAL}

Plant materials: The leaves of Capparis spinosa and Dodonaea viscose were collected from the region of Jabal Shuda in Albaha area in March 2018 and authenticated by Dr. Mohammed Abdalgadir, Department of Biology, College of Science and Arts, Albaha University, Almukhwah, Saudi Arabia. A voucher specimen was deposited at the Biology Department. Dried leaves of the two plant samples were ground and subsequently mixed with $2 \mathrm{~L}$ volumes of $80 \%$ aqueous ethanol. The slurry was placed at room temperature, after 3 days the extracts were filtered through Whatman filter paper. The extract concentrated and dried at room temperature to obtain the crude extracts.

Fractionation of ethanol extracts: The ethanol extracts were suspended in $300 \mathrm{~mL}$ distilled water and partitioned successively using organic solvents differ in their polarity (petroleum ether, chloroform, ethyl acetate and $n$-butanol). After evaporation of the solvents, the solid extracts were collected and dried.

Qualitative phytochemical analysis: Qualitative tests for detection of presence or absence of alkaloids, glycosides, cardiac glycosides, phenols, flavonoids, tannins, terpenoids, saponins and steroids were performed according to reported method [7].

\section{Determination of antioxidant activity}

Free radical-scavenging: The antioxidant screening used was depend on the scavenging potential of antioxidant(s) in plant material in respect of the free radical 1,1-diphenyl-2picrylhydrazyl (DPPH), which is dark magenta in colour, to yield the corresponding hydrazine with attendant colour change to pale red or yellowish red.

Free radical scavenging procedure: This method was performed based on the described procedure by Fenshyur et al. [8] with some modifications. Stock solution was get ready by dissolving $1 \mathrm{mg}$ of sample in $1 \mathrm{~mL}$ of absolute ethanol (98\%). Stock solution was reduced to ultimate concentrations of 100 , $50,25,12.5,6.25,3.125,1.5625 \mu \mathrm{g} / \mathrm{mL}$ in ethanol. Tris- $\mathrm{HCl}$ $(0.9 \mathrm{~mL})$ and $1 \mathrm{~mL}$ of $0.1 \mathrm{mM}$ DPPH in methanol solution were inserted to each concentration and incubated at room temperature in the dark for $30 \mathrm{~min}$. The absorbance of the resulting blend was read at $517 \mathrm{~nm}$ and transform to proportion antioxidant activity using the formulation beneath [8]:

$$
\text { Scavenging activity }(\%)=\frac{\left(\mathrm{A}_{\text {control }}-\mathrm{A}_{\text {sample }}\right)}{\mathrm{A}_{\text {control }}} \times 100
$$

Here, solution of $0.9 \mathrm{~mL}$ tris $\mathrm{HCl}+0.1 \mathrm{~mL}$ absolute ethanol + $1 \mathrm{~mL}$ absolute ethanol was used as blank, while solution of $0.9 \mathrm{~mL}$ tris $\mathrm{HCl}+0.1 \mathrm{~mL}$ absolute ethanol $+1 \mathrm{~mL} \mathrm{DPPH}$ was used as a control.

A recently intended DPPH solution shows a dark magenta colour with a extreme absorbance at $517 \mathrm{~nm}$. The magenta colour vanished when an antioxidant is ready in the place. Therefore, the alteration in the absorbance of reduced DPPH was used to estimate the potential of trial compound to do as free radical scavenger. Moreover, inhibitory concentration or $\mathrm{IC}_{50}$ value (concentration of antioxidant which make $50 \%$ lack of DPPH activity) was also used to evaluate the antioxidant activity of plant extract matched to the calibre medicine. The greater the antioxidant activity, the smaller is the amount of $\mathrm{IC}_{50}$ [9].

Total phenol: The concentration of phenolics in plant extracts was obtained using spectroscopic analysis technique with few experiment adjustments. Specimen solutions of extracts in the concentration of $1 \mathrm{mg} / \mathrm{mL}$ were used in the procedure. The reaction blend was set up by blending $0.5 \mathrm{~mL}$ of specimens solutions of extracts, $2.5 \mathrm{~mL}$ of $10 \%$ Folin-Ciocalteu's reagent resolved in water and $2.5 \mathrm{~mL} 7.5 \% \mathrm{NaHCO}_{3}$. Blank was simultaneously prepared, comprised $0.5 \mathrm{~mL}$ methanol, $2.5 \mathrm{~mL}$ of $10 \%$ Folin-Ciocalteu's reagent resolved in water and $2.5 \mathrm{~mL}$ of $7.5 \%$ of $\mathrm{NaHCO}_{3}$. The specimens were subsequently brood in a thermostat at $30^{\circ} \mathrm{C}$ for $90 \mathrm{~min}$. The absorbance was measured using spectrophotometer at $\lambda_{\max }=765 \mathrm{~nm}$. The specimens were intended three times for each analysis and the average value of absorbance was acquired. The same method was refined for the caliber solution of gallic acid and the calibration line was put up. Established on the deliberate absorbance, the concentration of phenolics was noted $(\mathrm{mg} / \mathrm{mL})$ from the calibration curve; then the content of phenolics in extracts was represent in terms of gallic acid equivalent ( $\mathrm{mg}$ of GAE/g of extract) [10].

\section{RESULTS AND DISCUSSION}

In present study, five types of extracts with petroleum ether, ethanol, chloroform, ethylacetate and $n$-butanol were prepared from two ethanolic crude extract of leaves of Dodonaea viscose and Capparis spinosa species. Qualitative as well as quantitative tests were performed on these extracts to assess their constituents and antioxidant potential values. The qualitative tests for various phytochemicals revealed the presence of saponins, alkaloids, terpenoids, carbohydrate, phenols, tannins and flavonoids are shown in Table-1.

Total phenolic contents (TPC): Phenolic compounds are natural products that are popularly existent in plants of high medicinal value. Phenolic compounds participate to the antioxidant potential of plants by neutralizing free radicals and forbidding decay of hydroperoxides into free radicals [11]. The ethyl acetate extract of Dodonaea viscose L. showed the highest TPC (351.59 $\pm 0.06 \mathrm{mg} / \mathrm{g} \mathrm{GAE})$ among all extracts tested, followed by $n$-butanol of $D$. viscose (231.98 $\pm 0.02 \mathrm{mg} / \mathrm{g}$ GAE), whereas crude ethanol, chloroform petroleum extract of $D$. viscose exhibited moderate TPC values (188.125 $\pm 0.03,154.9$ 
TABLE-1

RESULTS OF PHYTOCHEMICAL ANALYSIS OF Dodonaea viscose AND Capparis spinosa LEAVES EXTRACTS

\begin{tabular}{|c|c|c|c|c|c|c|}
\hline Extract & Flavonoid & Tannin & Alkaloid & Terponoid & Saponnin & Carbohydrate \\
\hline & \multicolumn{6}{|c|}{ Dodonaea viscose } \\
\hline Petroleum ether & + & + & + & + & - & + \\
\hline Chloroform & +++ & ++ & ++ & ++ & + & ++ \\
\hline Ethyl acetate & ++++ & +++ & - & ++ & +++ & +++ \\
\hline$n$-Butanol & ++ & +++ & - & + & +++ & +++ \\
\hline \multirow[t]{2}{*}{ Ethanol } & +++ & +++ & ++ & + & ++ & ++ \\
\hline & \multicolumn{6}{|c|}{ Capparis spinosa } \\
\hline Petroleum ether & - & - & + & - & - & - \\
\hline Chloroform & + & + & ++ & - & - & + \\
\hline Ethyl acetate & ++++ & +++ & + & - & ++ & ++ \\
\hline$n$-Butanol & ++ & +++ & - & - & + & ++ \\
\hline Ethanol & + & + & - & - & + & ++ \\
\hline
\end{tabular}

$+=$ Positive, $++=$ Good present, $+++=$ Strongly present, $-=$ Not detected

\pm 0.1 and $149.55 \pm 0.34 \mathrm{mg} / \mathrm{g} \mathrm{GAE})$, respectively. Lowest phenolic content among all extracts tested was found in ethanolic and $n$-butanol extract of Capparis spinosa leaves $(73.81 \pm 0.04$ and $128.32 \pm 0.4 \mathrm{mg} / \mathrm{g} \mathrm{GAE}$ ), respectively (Table-2).

TABLE-2

TOTAL PHENOLIC CONTENT

\begin{tabular}{lc}
\hline Sample extract & $\mathrm{mg} \mathrm{GAE} / \mathrm{g} \pm \mathrm{SD}$ \\
\hline Ethanol extract $($ D. viscose $)$ & $188.125 \pm 0.03$ \\
Petroleum ether extract $($ D. viscose $)$ & $149.550 \pm 0.34$ \\
Chloroform extract $($ D. viscose $)$ & $154.900 \pm 0.10$ \\
Ethyl acetate extract $($ D. viscose $)$ & $351.590 \pm 0.06$ \\
$n$-Butanol extract $($ D. viscose $)$ & $231.980 \pm 0.02$ \\
Ethanol extract $($ C. spinosa $)$ & $73.810 \pm 0.04$ \\
$n$-Butanol extract $($ C. spinosa $)$ & $128.320 \pm 0.40$ \\
\hline
\end{tabular}

DPPH radical scavenging activity: The antioxidant values of plant material was determined by $\mathrm{IC}_{50}$ amounts, indicating the concentration of the sample needed to recapture $50 \%$ of DPPH free radicals. It was noticed that DPPH radical scavenging activity of the examined extracts increased with the amount of plant material in the extract. The results revealed that the ethyl acetate extract of $D$. viscose leaves was highest in antioxidants among all extracts tested as denoted by low $\mathrm{IC}_{50}$ value of $0.00358 \pm 0.09 \mathrm{mg} / \mathrm{mL}$, followed by $n$-butanol extract of $D$. viscose leaves $(0.004 \pm 0.088 \mathrm{mg} / \mathrm{mL})$. The ethanolic extract of Capparis spinosa leaves exhibited lowest DPPH radical scavenging activity as depicted by high $\mathrm{IC}_{50}$ values $0.0707 \pm$ $0.15 \mathrm{mg} / \mathrm{mL}$ (Table-3).

TABLE-3

RESULTS OF ANTIOXIDANT ACTIVITY

\begin{tabular}{lcc}
\hline \multicolumn{1}{c}{ Sample } & $\begin{array}{c}\text { Activity \% } \\
\pm \mathrm{SD}\end{array}$ & $\begin{array}{c}\mathrm{IC}_{50} \mathrm{mg} / \mathrm{mL} \\
\pm \mathrm{SD}\end{array}$ \\
\hline Ethanol extract $($ D. viscose $)$ & $73.83 \pm 0.007$ & $0.01290 \pm 0.100$ \\
Petroleum ether extract $($ D. viscose $)$ & $71.20 \pm 0.003$ & $0.01670 \pm 0.180$ \\
Chloroform extract $($ D. viscose $)$ & $64.00 \pm 0.071$ & $0.05000 \pm 0.200$ \\
Ethylacetate extract $($ D. viscose $)$ & $76.58 \pm 0.024$ & $0.00358 \pm 0.090$ \\
n-Butanol extract $($ D. viscose $)$ & $76.30 \pm 0.015$ & $0.00400 \pm 0.088$ \\
Ethanol extract (C. spinosa) & $61.00 \pm 0.054$ & $0.07070 \pm 0.150$ \\
n-Butanol extract $($ C. spinosa) & $68.55 \pm 0.039$ & $0.04300 \pm 0.180$ \\
Gallic acid (standard) & 82.00 & 0.00442 \\
\hline
\end{tabular}

The climatic conditions, soil type, nutrition, biotic and abiotic stress etc. influence presence as well as amount of important phytochemicals in medicinal plants [12]. When in vitro studies on phytochemical contents and antioxidant potential in plant extracts were performed, factors such as choice of solvents, method of extraction, type of plant parts and location of collection of plant material, are important factors influencing reproducibility of the results [13]. It was reported by Bhoyar et al. [14] that factors such as choice of solvents, method of extraction, type of plant parts variation might be responsible for variation in the phytoconstituents of the medicinal plants. It is observed that variation occurred in phytochemical content and antioxidant potential of D. viscose and $C$. spinosa leaves extracts when extraction was performed by solvents differ in their polarities and the results are compared.

Diverse solvents resolve different biocompounds due to difference in their polarities. The agents influence the option of solvent are; amount of compound to be extracted, proportion of extraction, variety of different phytochemicals extracted, facility of subsequent treating of the extracts, poisoning of solvent in the biological activity procedure and potency health risk of the extractant [13]. Solvents differ in their polarities used in medicinal plants extraction are known to extract varying degrees of important phytocompounds and thus their comparative evaluation is necessary in determining the superiority of a particular solvent suit extraction of certain phytocompounds [15].

In present study, total phenolic contents and free radical scavenging activity of $D$. viscose and $C$. spinosa leaves extracts varied among the different plant parts extracted in various solvents. Leaves are found rich in phenolic compounds and antioxidants. Total phenolic contents assay showed highest phenolic content in ethyl acetate extract. High antioxidant activity estimated by DPPH assay was also observed in ethyl acetate and $n$-butanol extracts.

\section{Conclusion}

In present work, it was observed that the leaves extracts of D. viscose and C. spinosa from Jabal Shuda in Abaha area varied in their phytochemical constituents. The high phenolic content and high DPPH radical scavenging activity were exceptionally revealed in ethyl acetate. These results were supported by qualitative analysis as well as by quantitative assays included total phenolic content and DPPH assay profiling of extracts. This study explained the importance of crude aqueous extracts of dry plant leaves of D. viscose and C. spinosa from Jabal Shuda 
in Abaha area suitated in Saudi Arabia as important source of indigenous phytoconstituents and antioxidant complement, suggesting their powerful possibility to be used in traditional medicine system.

\section{ACKNOWLEDGEMENTS}

The authors are thankful to Albaha University, Saudi Arabia for providing the financial support for this research.

\section{CONFLICT OF INTEREST}

The authors declare that there is no conflict of interests regarding the publication of this article.

\section{REFERENCES}

1. J.I. Dibas, B.M. Yaghi, I.A. Mansi, N.M. Mhaidat and K.F.S. AlAbrouni, Res. J. Pharm. Biol. Chem. Sci., 8, 489 (2017).

2. A. Jain, Am. J. Life Sci., 2, 292 (2014); https://doi.org/10.11648/j.ajls.20140205.17.;

3. P. Yadav and N. Malpathak, Indian J. Pharm. Educ. Res., 50, 495 (2016); https://doi.org/10.5530/ijper.50.3.25.

4. T. Riaz, A. Abbasi, A. Aziz-Ur-Rehman, T. Shahzadi, M. Ajaib and M. Khan, J. Serb. Chem. Soc., 77, 423 (2012); https://doi.org/10.2298/JSC110621183R.
5. M. Li, P.W. Pare, J. Zhang, T. Kang, Z. Zhang, D. Yang, K. Wang and H. Xing, Rec. Nat. Prod., 12, 239 (2018); https://doi.org/10.25135/rnp.24.17.08.138.

6. H. Akkari, B. chir F, S. Hajaji, M. Rekik, E. Sebai, H. Hamza, M.A. Darghouth and M. Gharbi, Vet. Med. (Praha), 61, 308 (2016); https://doi.org/10.17221/169/2015-VETMED.

7. J.B. Harborne Phytochemical Methods, A Guide to Modern Techniques of Plant Analysis, edn 4, pp. 1-5, 182-91 (1973).

8. L.Fenshyur, J. H. Tsung, J.H.Chen, C.Y. Chiu and C.-Pinglo, Int. J. Appl. Sci. Eng., 3, 195 (2005).

9. P. Molyneux, Songklanakarin J. Sci. Technol., 26, 211 (2004).

10. V. Singleton, R. Orthofer and R.M. Lamuela-Raventós, Methods Enzymol., 299, 152 (1999); https://doi.org/10.1016/S0076-6879(99)99017-1.

11. S. Chanda and R. Dave, African J. Microbiol. Res., 3, 981 (2009).

12. J.A. Domínguez-Avila, E. Alvarez-Parrilla, G.A. González-Aguilar, J. Villa-Rodríguez, G.I. Olivas-Orozco, J. Molina Corral, M.C. GómezGarcía and L.A. De la Rosa, J. Food Res., 2, 143 (2013); https://doi.org/10.5539/jfr.v2n5p143.

13. P. Tiwari, B. Kumar, M. Kaur, G. Kaur and H. Kaur, Int. Pharm. Sci., 1, 98 (2011).

14. M.S. Bhoyar, G.P. Mishra, P.K. Naik and R.B. Srivastava, Aust. J. Crop Sci., 5, 912 (2011).

15. A. Jain, P. Sinha and N Desai, Int. J. Pharm. Sci. Drug Res., 5, 1320 (2014). 